\title{
Determination of alkylamines in atmospheric aerosol particles: a comparison of gas chromatography-mass spectrometry and ion chromatography approaches
}

\author{
R.-J. Huang ${ }^{1,3,4}$, W.-B. Li ${ }^{2}$, Y.-R. Wang ${ }^{2}$, Q. Y. Wang ${ }^{5}$, W. T. Jia ${ }^{5}$, K.-F. Ho ${ }^{5,6}$, J. J. Cao ${ }^{5}$, G. H. Wang ${ }^{5}$, X. Chen ${ }^{2}$, \\ I. EI Haddad ${ }^{1}$, Z. X. Zhuang ${ }^{2,7}$, X. R. Wang ${ }^{2,7}$, A. S. H. Prévôt ${ }^{1}$, C. D. O'Dowd ${ }^{3}$, and T. Hoffmann ${ }^{4}$ \\ ${ }^{1}$ Laboratory of Atmospheric Chemistry, Paul Scherrer Institute (PSI), 5232 Villigen, Switzerland \\ ${ }^{2}$ Department of Chemistry and The MOE Key Laboratory of Spectrochemical Analysis \& Instrumentation, \\ College of Chemistry and Chemical Engineering, Xiamen University, Xiamen 361005, China \\ ${ }^{3}$ Centre for Climate and Air Pollution Studies, Ryan Institute, National University of Ireland Galway, University Road, \\ Galway, Ireland \\ ${ }^{4}$ Institute of Inorganic and Analytical Chemistry, Johannes Gutenberg University of Mainz, Duesbergweg 10-14, \\ 55128 Mainz, Germany \\ ${ }^{5}$ Key Laboratory of Aerosol Chemistry \& Physics, SKLLQG, Institute of Earth Environment, \\ Chinese Academy of Sciences, Xi' an 710075, China \\ ${ }^{6}$ School of Public Health and Primary Care, The Chinese University of Hong Kong, Hong Kong, China \\ ${ }^{7}$ Center for Environmental Science and Technology, Xiamen Huaxia Vocational College, Xiamen 361024, China
}

Correspondence to: R.-J. Huang (rujin.huang@psi.ch)

Received: 29 January 2014 - Published in Atmos. Meas. Tech. Discuss.: 5 March 2014

Revised: 1 June 2014 - Accepted: 3 June 2014 - Published: 4 July 2014

\begin{abstract}
In recent years low molecular weight alkylamines have been recognized to play an important role in particle formation and growth in the lower atmosphere. However, major uncertainties are associated with their atmospheric processes, sources and sinks, mostly due to the lack of ambient measurements and the difficulties in accurate quantification of alkylamines at trace level. In this study, we present the evaluation and optimization of two analytical approaches, i.e., gas chromatography-mass spectrometry (GC-MS) and ion chromatography (IC), for the determination of alkylamines in aerosol particles. Alkylamines were converted to carbamates through derivatization with isobutyl chloroformate for GCMS determination. A set of parameters affecting the analytical performances of the GC-MS approach, including reagent amount, reaction time and $\mathrm{pH}$ value, was evaluated and optimized. The accuracy is $84.3-99.1 \%$, and the limits of detection obtained are $1.8-3.9 \mathrm{pg}$ (or $0.02-0.04 \mathrm{ng} \mathrm{m}^{-3}$ ). For the IC approach, a solid-phase extraction (SPE) column was used to separate alkylamines from interfering cations before IC analysis. 1-2\% (v/v) of acetone (or $2-4 \%(\mathrm{v} / \mathrm{v})$ of
\end{abstract}

acetonitrile) was added to the eluent to improve the separation of alkylamines on the IC column. The limits of detection obtained are 2.1-15.9 $\mathrm{ng}$ (or 0.9-6.4 $\mathrm{ng} \mathrm{m}^{-3}$ ), and the accuracy is $55.1-103.4 \%$. The lower accuracy can be attributed to evaporation losses of amines during the sample concentration procedure. Measurements of ambient aerosol particle samples collected in Hong Kong show that the GC-MS approach is superior to the IC approach for the quantification of primary and secondary alkylamines due to its lower detection limits and higher accuracy.

\section{Introduction}

Organic nitrogen $(\mathrm{ON})$ is ubiquitous in the atmosphere, and yet a poorly characterized component of atmospheric aerosols. Compared to oxygenated organics which have been extensively studied in the past decade (Hallquist et al., 2009; Hoffmann et al., 2011), much less attention has been devoted to $\mathrm{ON}$ in atmospheric aerosols, and thus the sources, 
composition and atmospheric processes of ON are poorly constrained. Addition of nitrogen to an organic structure can increase the potential carcinogenic and mutagenic effects (Kameda, 2011) as well as the extinction coefficient of a compound (Nguyen et al., 2011). It can also increase the hygroscopicity of aerosols and thereby the ability to act as cloud condensation nucleus because several organic nitrogen groups (e.g., amines and nitrates) have high water solubility. Therefore, it is crucial to understand the ON composition in order to get better knowledge of aerosol effects on health, air quality and climate.

Among a wide variety of $\mathrm{ON}$, amines are unique in their base-stabilization capacity. Especially, low molecular weight aliphatic amines such as dimethylamine and ethylamine can substantially enhance the ternary nucleation of sulfuric acid particles by a stepwise accretion of the basic molecules and concomitant addition of acid molecules in the critical clusters (Kirkby et al., 2011). The formation of aminium salts from heterogeneous reactions of amines with organic and inorganic acids can further contribute to post-nucleation growth of nanoparticles, which increases the particle number concentration by preventing coagulation from pre-existing particles (Angelino et al., 2001; Murphy et al., 2007; Wang et al., 2010; Smith et al., 2010). The reactive uptake of amines and subsequent displacement of ammonium on the particles provide an additional pathway for gas-to-particle conversion of amines (Qiu et al., 2011; Chan and Chan, 2012). The mechanisms discussed above support the observations of ambient particle-phase amines in various domains such as in boreal forests (Mäkelä et al., 2001; Smith et al., 2010), in urban and rural areas (Pratt et al., 2009; Smith et al., 2010; VandenBoer et al., 2011; Huang et al., 2012), and in the remote marine boundary layer (Facchini et al., 2008; Miyazaki et al., 2011).

Amines have been measured so far in atmospheric ultrafine and fine particles by a number of online mass spectrometric techniques including compact time-of-flight aerosol mass spectrometry (C-TOF-AMS) (Sorooshian et al., 2008), aerosol time-of-flight mass spectrometry (ATOFMS) (Huang et al., 2012), atmospheric pressure interface time-of-flight mass spectrometry (APi-TOF-MS) (Junninen et al., 2010), and thermal desorption chemical ionization mass spectrometry (TDCIMS) (Smith et al., 2010). However, these mass spectrometric observations cannot provide quantitative determination of specific amines. For example, AMS response factors for various aminium salts have been reported to vary as much as 10 times that of ammonium nitrate depending on the composition of the salt, which limit the method to amine identification only (Silva et al., 2008). The TDCIMS analysis reported the levels of amines as the molar ratio of average ion abundance for each aminium compound to the total average ion abundance observed, rather than as the absolute concentrations (Smith et al., 2010).

Quantitative determination of amines in ambient aerosol particles is mainly based on chromatographic techniques such as ion chromatography (IC) (Henning et al., 2003;
Facchini et al., 2008; Erupe et al., 2010; VandenBoer et al., 2011; Praplan et al., 2012), gas chromatography (GC) (Akyüz, 2008) and high-performance liquid chromatography (HPLC) (Yang et al., 2005; Müller et al., 2009; Ruiz-Jiménez et al., 2012). IC allows the determination of low molecular weight alkylamines including tertiary amines without derivatization. However, certain amines are often co-eluted as a single peak (e.g., diethylamine and trimethylamine) or interfered by other abundant cations present in aerosol particles (e.g., $\mathrm{NH}_{4}^{+}$and $\mathrm{K}^{+}$) (VandenBoer et al., 2011) due to the low separation efficiency and resolution of IC. For determination with GC and HPLC, the derivatization of amines is generally mandatory to improve the separation efficiency and the detection limits. The typical derivatization reagents for amines include $o$-phthaldialdehyde, dansyl chloride, isobutyl chloroformate, and 4-nitrophenyl trifluoroacetate (Pan et al., 1997; Akyüz 2008; Huang et al., 2009; Ruiz-Jiménez et al., 2012). Nevertheless, the derivatization reagents are suitable only for primary and secondary amines, but not for tertiary amines due to the absence of a replaceable hydrogen atom.

In this paper, we present two analytical approaches (i.e., gas chromatography-mass spectrometry (GC-MS) and IC) for the determination of alkylamines in aerosol particles. We focused on $\mathrm{C}_{1}-\mathrm{C}_{6}$ alkylamines because these low molecular weight alkylamines are thought to release to the atmosphere in the largest quantity. The parameters affecting the analytical performances of both methods are extensively evaluated and optimized.

\section{Experimental}

\subsection{Standards and $\mathbf{P M}_{2.5}$ samples}

A $2.0 \mathrm{mg} \mathrm{mL}^{-1}$ stock standard solution was prepared in $0.1 \mathrm{M} \mathrm{HCl}$ aqueous solution, which contains a mixture of the hydrochloride salts of methylamine (MA, 99\%, J\&K Scientific), dimethylamine (DMA, $>99 \%$, Aladdin Chemical), trimethylamine (TMA, > $98 \%$, Sigma Aldrich), ethylamine (EA, $>98 \%$, Tokyo Chemical Industry), diethylamine (DEA, $>98.5 \%$, Tokyo Chemical Industry), triethylamine (TEA, $>98.5 \%$, Tokyo Chemical Industry), $n$ propylamine (PA, $>99 \%$, Acros) and $n$-butylamine (BA, $>98 \%$, Tokyo Chemical Industry). A series of working standard solutions was prepared by sequential dilution of the stock standard solution. The alkaline methanol solution was prepared by dissolving $\mathrm{KOH}$ in methanol until saturation, followed by filtration through a $0.45 \mu \mathrm{m}$ filter. All other chemicals used were of analytical reagent grade. Deionized water $(18 \mathrm{M} \Omega \mathrm{cm})$ was used for preparation of all aqueous solutions.

The 24-hour integrated $\mathrm{PM}_{2.5}$ (particulate matter with an aerodynamic diameter $<2.5 \mu \mathrm{m}$ ) samples were collected on pre-fired $\left(500^{\circ} \mathrm{C}, 3 \mathrm{~h}\right)$ quartz filters $\left(8^{\prime \prime} \times 10^{\prime \prime}\right)$ in August and November 2011 and February and May 2012 (24 samples 
and 4 field blanks) in Tung Chung, Hong Kong $\left(22^{\circ} 17^{\prime} 20^{\prime \prime} \mathrm{N}\right.$, $113^{\circ} 56^{\prime} 37^{\prime \prime} \mathrm{E}$ ) by using high-volume air samplers. A portion was taken from each filter and placed into a $15 \mathrm{~mL}$ screw capped brown vial to which $5 \mathrm{~mL} 0.1 \mathrm{M} \mathrm{HCl}$ was added. The samples were extracted in an ultrasonic bath at room temperature for $15 \mathrm{~min}$. This extraction procedure was repeated 3 times. Finally, the extracts were combined for each filter and filtered with $0.2 \mu \mathrm{m}$ syringe filter (PTFE membrane).

\subsection{GC-MS analysis}

The sample extracts and standard solution were subjected to derivatization before the GC-MS analysis. To $15 \mathrm{~mL}$ of filtered extracts (or standard solution), $5 \mathrm{~mL}$ of phosphate buffer (pH 10), $5 \mathrm{~mL}$ of toluene and $200 \mu \mathrm{L}$ of isobutyl chloroformate (IBCF) were added. The solution was shaken in a mechanical shaker at room temperature for $15 \mathrm{~min}$. The toluene extracts containing the target analytes were then transferred to another vial and concentrated to $1 \mathrm{~mL}$ under a gentle $\mathrm{N}_{2}$ stream at room temperature; $500 \mu \mathrm{L}$ of alkaline methanol was added to the concentrated extracts, and the mixture was shaken for $5 \mathrm{~min}$ for removal of the excess of IBCF. $1.5 \mathrm{~mL}$ of $1 \mathrm{M} \mathrm{NaOH}$ was subsequently added, and the mixture was shaken for another $5 \mathrm{~min}$.

The mixture was centrifuged and $1.0 \mu \mathrm{L}$ of the toluene extracts was injected into a GC-MS system (Shimadzu QP 2010 Plus, Shimadzu, Japan). A fused-silica capillary column $\left(30 \mathrm{~m} \times 0.25 \mathrm{~mm}\right.$ i.d., $d_{\mathrm{f}}$ : $0.25 \mu \mathrm{m}$, Rxi-5MS, Shimadzu, Japan) was used for chromatographic separation. High-purity helium $(99.999 \%)$ was used as a carrier gas at a constant flow of $1.0 \mathrm{~mL} \mathrm{~min}^{-1}$. The temperature of the injector was set to $280^{\circ} \mathrm{C}$, and the transfer line was $280^{\circ} \mathrm{C}$. The temperature of the $\mathrm{GC}$ oven was programmed as follows: initial temperature $80^{\circ} \mathrm{C}$ (hold $3 \mathrm{~min}$ ), $5^{\circ} \mathrm{C} \mathrm{min}^{-1}$ to $140^{\circ} \mathrm{C}$ (hold $3 \mathrm{~min}$ ), and then $30^{\circ} \mathrm{C} \mathrm{min}^{-1}$ to $200^{\circ} \mathrm{C}$ (hold $3 \mathrm{~min}$ ). The MS was operated in the electron impact (EI) ionization mode with an acceleration energy of $70 \mathrm{eV}$. A solvent delay of $4.0 \mathrm{~min}$ preceded the MS spectra acquisition in the full-scan mode (in the range $m / z, 30-450$ ) or in the selected ion monitoring (SIM) mode in the following sequence: $4.00-6.15 \mathrm{~min}, \mathrm{~m} / z: 57$, 58,$116 ; 6.15-6.50 \mathrm{~min}, \mathrm{~m} / z: 72,130,145 ; 6.50-7.86 \mathrm{~min}$, $m / z: 57,72,130 ; 7.86-9.25 \mathrm{~min}, \mathrm{~m} / z: 57,158,173$; 9.25$10.69 \mathrm{~min}, m / z: 57,86,144 ; 10.69-12.56 \mathrm{~min}, m / z: 57,100$, 173. The use of SIM mode is an advantage for eliminating potential interference from sample matrix (or from the sample pretreatment steps) because it greatly enhances the selectivity (by monitoring characteristic $\mathrm{m} / \mathrm{z}$ fragments) and sensitivity of the method. The analytes are identified when the following two criteria are met: (1) the chromatographic peaks for the unknown and standard samples coincide in retention time, and (2) the intensity ratios of the characteristic $m / z$ of the unknown and standard peaks agree within $\pm 15 \%$.

\subsection{IC analysis}

$15 \mathrm{~mL}$ aliquots of filtered extracts were passed through a cleaned and conditioned cation-exchange solid-phase extraction column (SPE, Oasis MCX, Waters). The analytes were eluted using $3 \mathrm{~mL}$ of $\mathrm{NH}_{3} /$ methanol $(5: 95$, v/v) solutions. The resulting eluate was adjusted to $\mathrm{pH} 8.8$ and then concentrated to $1 \mathrm{~mL}$ under a gentle $\mathrm{N}_{2}$ stream at room temperature. A $25 \mu \mathrm{L}$ aliquot of the concentrated eluate (or standard solution) was injected into a Metrohm 861 IC analytical system with non-suppressed detection (Metrohm, 861 Advanced Compact IC). The IC was equipped with a dual-piston pump, a degas assembly and digital conductivity detection. Analysis was accomplished with a Metrosep C4 (150 $\mathrm{mm} \times 4 \mathrm{~mm}$ i.d. $)$ with Metrosep C4 guard column, which was chosen due to its advantage in the analysis of amines and common inorganic cations with non-suppressed conductivity detection. The optimized eluent solution contained $6 \mathrm{mMHNO}_{3} / 1.0 \%(\mathrm{v} / \mathrm{v})$ acetone solution at a flow rate of $0.4 \mathrm{~mL} \mathrm{~min}^{-1}$. Separation was carried out under isocratic conditions and at a room temperature of approximately $20^{\circ} \mathrm{C}$. Data processing was performed with IC Net 2.3 software.

\subsection{Quality assurance}

For every 10 samples, a procedural blank and a spiked sample - namely, real ambient samples spiked with known amounts of standard solution of amines to be analyzed - were measured to check for interference and cross-contamination. External standard method was used for quantitative determination of the analytes. Because carbamates are not commercially available, the calibration curves were made by derivatizing the standard solutions of amines following the same procedures used for real samples. It may minimize potential artifacts from the sample pretreatment steps, where both standard solutions and real samples are subjected to same artifacts (if any). The limits of detection are defined as the minimum detectable peaks of individual species with a signal-tonoise $(\mathrm{S} / \mathrm{N})$ ratio of $3: 1$. The recoveries were determined by the analysis of the spiked samples: we first measured a filter punch without spike and then measured the second punch from the identical filter that was spiked with known amounts of standard solution of amines. The differences between these two measurements were divided by amounts of amines spiked to calculate the recoveries of individual amines. This recovery test also provides an indication of potential matrix effect. The reproducibility (relative standard deviation, RSD) was determined by measuring five identical samples that were subjected to the same pretreatment procedure. Four field blank samples were collected and measured, giving the average field blank values as follows: $0.04 \mathrm{ng} \mathrm{m}^{-3} \mathrm{MA}$, $1.10 \mathrm{ng} \mathrm{m}^{-3}$ DMA, $<0.03 \mathrm{ng} \mathrm{m}^{-3}$ EA, $1.22 \mathrm{ng} \mathrm{m}^{-3}$ DEA, $0.29 \mathrm{ng} \mathrm{m}^{-3} \mathrm{PA}$, and $0.28 \mathrm{ng} \mathrm{m}^{-3} \mathrm{BA}$. All data reported here were corrected for the field blanks. 


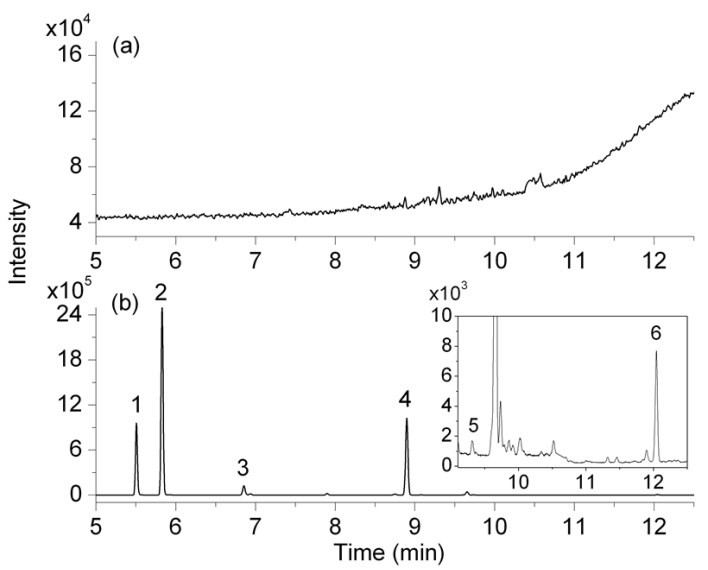

Figure 1. Typical GC-MS chromatograms for the analysis of alkylamines in ambient aerosol sample before (a) and after (b) derivatization with the derivatizing agent IBCF. Peak assignments: (1) MA, (2) DMA, (3) EA, (4) DEA, (5) PA and (6) BA.

\section{Results and discussion}

\subsection{Determination of amines with GC-MS}

\subsubsection{Effect of $\mathrm{pH}$ on the derivatization}

The low molecular weight alkylamines are not detectable without derivatization when injected into a nonpolar GC column (5\% diphenyl $95 \%$ dimethylpolysiloxane) (see Fig. 1a), due to their high volatilities and high polarities as reflected in their boiling points and oil-water partition coefficients $\log P_{\mathrm{o} / \mathrm{w}}$ (see Table 1). The formation of carbamate derivatives via reactions with isobutyl chloroformate (IBCF) (Akyüz, 2008) can significantly improve the chromatographic properties of primary and secondary amines, leading to well-resolved peaks on the GC chromatogram (Fig. 1b), because the carbamates have lower volatilities and polarities as well as higher thermal stabilities compared to the amines. The derivatization proceeds rapidly in aqueous alkaline media since it promotes the deprotonation of aminium (Reaction R1). The latter are the most likely form of amines in ambient aerosol particles. High $\mathrm{pH}$ values also shift the derivatization reaction to the product side through neutralization of the $\mathrm{H}^{+}$formed in this reaction (R2).

$$
\mathrm{RR}^{\prime} \mathrm{NH}_{2}^{+} \stackrel{\mathrm{pK}_{\mathrm{a}}}{\leftrightarrows} \mathrm{RR}^{\prime} \mathrm{NH}+\mathrm{H}^{+}\left(\mathrm{R}=\text { alkyl, } \mathrm{R}^{\prime}=\text { alkyl or } \mathrm{H}\right)
$$

$$
\begin{array}{r}
\mathrm{RR}^{\prime} \mathrm{NH}+\mathrm{ClCOOCH}_{2} \mathrm{CH}\left(\mathrm{CH}_{3}\right)_{2} \rightarrow \\
\mathrm{RR}^{\prime} \mathrm{NCOOCH}_{2} \mathrm{CH}\left(\mathrm{CH}_{3}\right)_{2}+\mathrm{H}^{+}+\mathrm{Cl}^{-} .
\end{array}
$$

Figure 2 shows the effect of $\mathrm{pH}$ values on the derivatization efficiencies of MA, DMA, EA, DEA, PA and BA. When the $\mathrm{pH}$ value is below 7, most amines remain in the protonated form that cannot react with IBCF to form the carbamate derivatives. The derivatization proceeds progressively

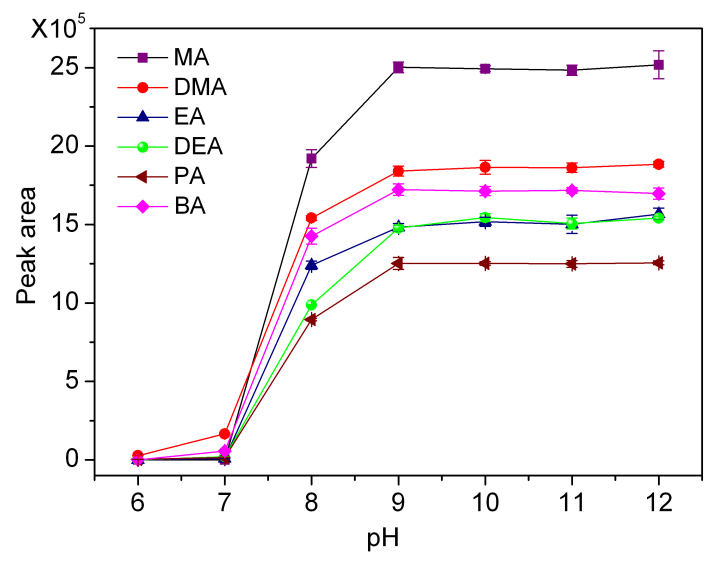

Figure 2. Effect of $\mathrm{pH}$ on the derivatization efficiency of different alkylamines. The $\mathrm{pH}$ of the solution was adjusted with $1 \mathrm{MHCl}$ or $1 \mathrm{M} \mathrm{NaOH}$ and measured with a $\mathrm{pH}$ meter.

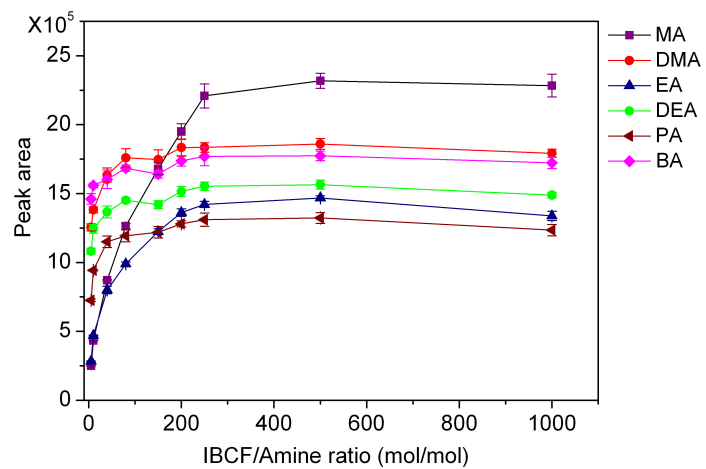

Figure 3. Effect of the IBCF amount on the derivatization efficiency of different alkylamines.

with the increase of the $\mathrm{pH}$ value and reaches the maximum efficiencies for all investigated alkylamine when the $\mathrm{pH}$ values are higher than 9. This $\mathrm{pH}$ threshold is somewhat lower than the theoretical values $\left(\mathrm{pK}_{\mathrm{a}}+1\right.$, i.e., 11.58-12.09), where the amines are mostly present in the neutralized form that can react with IBCF. This phenomenon can be explained by the removal of derivatives from the aqueous solution by toluene which, together with the neutralization of the $\mathrm{H}^{+}$formed, accelerates the shifting of reactions (R1 and $\mathrm{R} 2$ ) to the right. Therefore, $\mathrm{pH} 10$ was selected as the optimized value in this study.

\subsubsection{Effect of reagent amount and reaction time on the derivatization efficiency}

Figure 3 shows that, compared to the theoretical molar ratio of $1: 1$ for the derivatization of amines with IBCF, a much higher IBCF/ amine ratio is needed to ensure a sufficient efficiency. Interestingly, the derivatization efficiency for DMA, DEA, PA and BA is much higher than for MA and EA at a low IBCF/amine ratio. For example, at the IBCF/amine 
Table 1. The physicochemical parameters of alkylamines.

\begin{tabular}{lrrrr}
\hline $\begin{array}{l}\text { Alkyl- } \\
\text { amine }\end{array}$ & $\begin{array}{r}\text { Boiling } \\
\text { point, }{ }^{\circ} \mathrm{C}\end{array}$ & $\begin{array}{r}\text { Vapor pressure, } \\
\mathrm{kPa} \text { at } 20{ }^{\circ} \mathrm{C}\end{array}$ & $\begin{array}{r}\mathrm{pK}_{\mathrm{a}}, \\
25^{\circ} \mathrm{C}\end{array}$ & $\begin{array}{r}\text { Oil water distribution } \\
\text { coefficient, } \log P_{\mathrm{o} / \mathrm{w}}\end{array}$ \\
\hline MA & -7 & 186.1 & 10.66 & -0.173 \\
DMA & 7 & 170.3 & 10.73 & -0.38 \\
TMA & 3.5 & 91.7 & 9.8 & -0.152 \\
EA & 17 & 116.5 & 10.8 & -0.177 \\
DEA & 56 & 26.0 & 11.09 & -0.109 \\
TEA & 90 & 6.9 & 10.24 & 1.45 \\
PA & 49 & 33.0 & 10.58 & -0.184 \\
BA & 77.8 & 9.1 & 10.62 & 3.56 \\
\hline
\end{tabular}

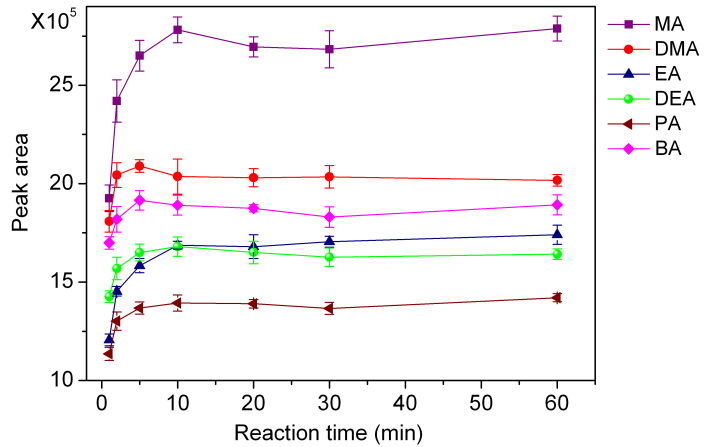

Figure 4. Time-dependent derivatization of different alkylamines.

molar ratio of 5-10, the efficiency is around $80 \%$ for DMA, DEA, PA and BA, but only about $20 \%$ for MA and EA. This can be attributed to the increased number and/or chain length of the alkyl group(s) in DMA, DEA, PA and BA, which enhances the electron density at the nitrogen atoms of these amines and thereby their nucleophilic reactivity towards the derivatization agent IBCF. The DMA, DEA, PA and $\mathrm{BA}$ approach their maximum derivatization efficiencies at the IBCF/ amine molar ratios $>100$, while the molar ratios are $>250$ in the case of MA and EA. Given that IBCF can also react with certain amino acids (Sobolevsky et al., 2004), an equivalent molar ratio of IBCF / amine of 500 was selected for the analysis of real samples.

With the optimized $\mathrm{pH}$ value and IBCF/amine molar ratio, the derivatization of amines with IBCF is very efficient. The temporal behavior of the derivatization efficiency is shown in Fig. 4. Quantitative determinations were achieved for DMA, DEA, PA and BA after about $5 \mathrm{~min}$ and for MA and EA after $10 \mathrm{~min}$, respectively. Again, the faster derivatization of DMA, DEA, PA and BA, compared to that of MA and EA, is due to their enhanced nucleophilic reactivity towards IBCF.

\subsection{Determination of amines with IC}

\subsubsection{Effect of eluent solution on the separation}

IC has been used for the determination of amines in atmospheric samples in previous studies (Facchini et al., 2008; Erupe et al., 2010; VandenBoer et al., 2011; Praplan et al., 2012). However, measurements of the full range of species investigated in this study have not been reported so far. The commercial IC columns are designed for the separation of inorganic cations, limiting their ability to fully resolve protonated organics such as alkylamines from inorganic cations. Baseline resolution of alkylamines is particularly challenging due to their similar solvation characteristics. For example, VandenBoer et al. (2011) observed the co-elution of DMA and $\mathrm{NH}_{4}^{+}$on the Dionex CS12A column and the co-elution of DEA and TMA on the Dionex CS17 column. When using $6 \mathrm{mM} \mathrm{HNO}_{3}$ aqueous solution as eluent solution, we also observed poor separation and poor peak shape of DEA, TMA and BA on the Metrosep C4 column (see Fig. 5a), leading to difficulties in retrieving accurate peak area integrations. However, improved resolution was realized with the addition of $2-4 \%(\mathrm{v} / \mathrm{v})$ acetonitrile to the eluent solution. The addition of acetonitrile also led to the detection of TEA which, compared with other investigated alkylamines, has the strongest interaction with the stationary phase of the IC column and thus was not eluted within the time window of 20 min with $\mathrm{HNO}_{3}$ eluent alone. Further increase of the acetonitrile fraction (5-8\%) in the eluent solution resulted in poor resolution for MA, EA, PA and DEA (Fig. 5a). We observed similar effects from acetone on the separation of alkylamines: the best resolution was achieved when 1-2\% of acetone was added to the eluent solution $\left(6 \mathrm{mM} \mathrm{HNO}_{3}\right)$, but the resolution became progressively worse when the acetone fraction was increased from 3 to $10 \%$ (Fig. 5b).

\subsubsection{Influence of interfering cations}

A common issue associated with IC analysis of alkylamines is the interference from inorganic cations such as $\mathrm{Na}^{+}, \mathrm{K}^{+}$, $\mathrm{Mg}^{2+}, \mathrm{Ca}^{2+}$ and $\mathrm{NH}_{4}^{+}$, which are typically 1-3 orders of 

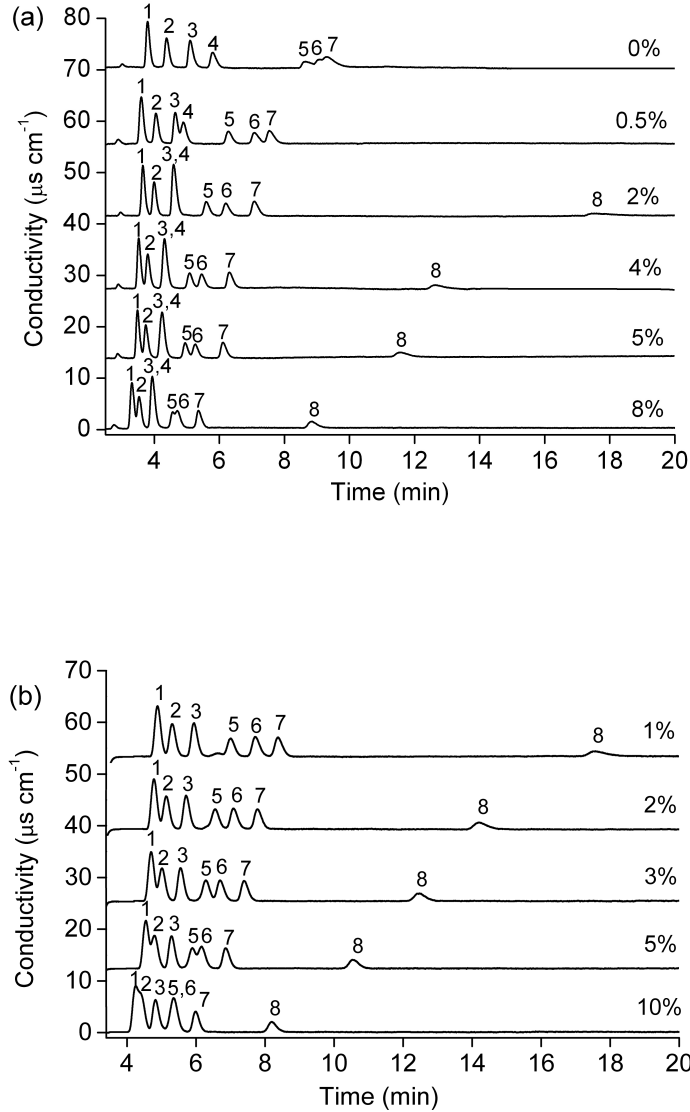

Figure 5. Effect of the addition of acetonitrile (a) and acetone (b) in eluent solution $\left(6 \mathrm{mM} \mathrm{HNO}_{3}\right)$ on the IC separation of alkylamines. Peak assignments: (1) MA, (2) EA, (3) DMA, (4) PA, (5) BA, (6) DEA, (7) TMA and (8) TEA. Note that PA was not studied in (b) because its concentration is very low in the ambient samples of this study $\left(\leq 0.4 \mathrm{ng} \mathrm{m}^{-3}\right)$, as measured by the GC-MS method.

magnitude more concentrated than alkylamines (Müller et al., 2009; VandenBoer et al., 2011). Co-elution of these interfering cations with the analytes may be problematic for the quantification of alkylamines. As shown in Fig. 6a, MA and $\mathrm{K}^{+}$, DMA and $\mathrm{Mg}^{2+}$, and $\mathrm{BA}$ and $\mathrm{Ca}^{2+}$ co-elute on the Metrosep C4 column. To minimize such interference the solid-phase extraction (SPE) cartridges were used before IC analysis. It was found that the Oasis MCX cationexchange cartridges can efficiently remove most of the interfering cations (Fig. 6b). However, it was also observed that some alkylamines were lost by evaporation during the concentration step after SPE treatment. The evaporation loss is particularly significant for MA $(\sim 40 \%)$, DMA $(\sim 35 \%)$ and TMA $(\sim 85 \%)$, most probably because they are much more volatile than other alkylamines. Interestingly, the loss for MA and DMA is smaller than that for TMA although the former two species have higher vapor pressure compared to TMA. One explanation for this observation is the potential interaction of MA (DMA) with solvent molecules by

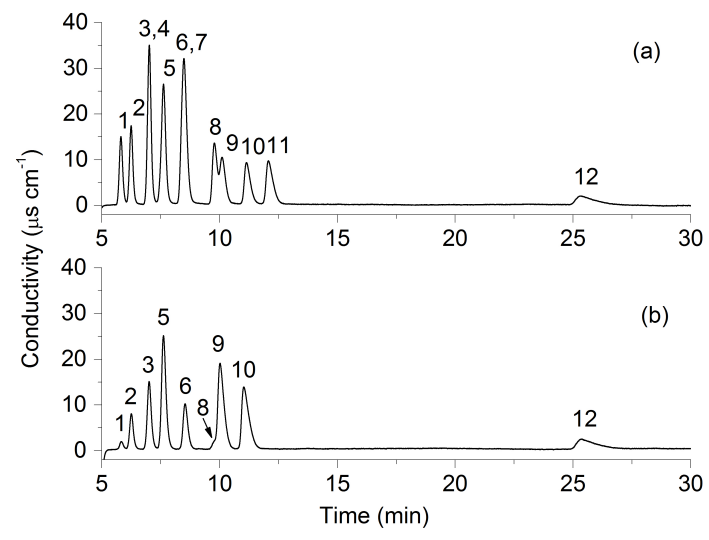

Figure 6. IC chromatograms of alkylamines before (a) and after (b) SPE pre-separation to minimize the interfering ions. Peak assignments: (1) $\mathrm{Na}^{+}$, (2) $\mathrm{NH}_{4}^{+}$, (3) MA, (4) $\mathrm{K}^{+}$, (5) EA, (6) DMA, (7) $\mathrm{Mg}^{2+},(8) \mathrm{Ca}^{2+}$, (9) BA, (10) DEA, (11) TMA and (12) TEA. Note that $\sim 85 \%$ of TMA (estimated by testing $10-, 20$ - and 30factor concentrated TMA standard solutions) was lost by evaporation during the concentration step after SPE, reflected in the absence of TMA peak in (b).

hydrogen bonding, which compensates for their high volatility. The evaporation loss can be reduced by decreasing the $\mathrm{pH}$ value of the solution due to the transformation of alkylamines to their protonated salts, which significantly decreases the volatility. The optimized $\mathrm{pH}$ value is 8.8 , where the interference from $\mathrm{NH}_{3}\left(\mathrm{pK}_{\mathrm{a}}\right.$ 9.25) and losses of alkylamines are minimized.

\subsection{Comparison of the methods}

Table 2 shows the reproducibility, recovery and limit of detection (LOD) of the IC and GC-MS methods. The precision of the IC (2.4-15.7\% RSD) and GC-MS (1.7-6.2\% RSD) methods can be considered to be very satisfactory in view of multiple sources of error that contributed to total RSD values (e.g., error from sample pretreatment and error of the IC and GC-MS detection). The recoveries, determined by analyzing ambient samples spiked with known amounts of amine standards, range from $84.3 \%$ to $99.1 \%$ for the GC-MS method and from $55.1 \%$ to $103.4 \%$ for the IC method. The good recoveries provided by the GC-MS method indicate high derivatization efficiency and low sample matrix effect. The relatively low recoveries of the IC method for MA, DMA and TMA can be attributed to evaporation losses during the concentration procedure as discussed above. The LODs $(\mathrm{S} / \mathrm{N}=3)$ of the GC-MS method $(1.8-3.9 \mathrm{pg})$ are about 3 orders of magnitude lower than those of the IC method (2.115.9 ng; see Table 2).

Figure 7 shows the concentrations of ambient particulate alkylamines at a background site in Hong Kong, measured by both GC-MS and IC methods. The concentrations measured by the GC-MS method are slightly higher than those 
Table 2. The analytical performance of GC-MS and IC method.

\begin{tabular}{|c|c|c|c|c|c|c|c|c|}
\hline \multirow{2}{*}{ Alkylamine } & \multicolumn{4}{|c|}{ GC-MS } & \multicolumn{4}{|c|}{ IC } \\
\hline & $\begin{array}{r}\text { Reproducibility } \\
\% \\
(n=5)\end{array}$ & $\begin{array}{r}\text { Recovery } \\
\% \\
(n=3)\end{array}$ & $\begin{array}{r}\mathrm{LOD}(\mathrm{pg}), \\
\text { injection volume } \\
1 \mu \mathrm{L}(n=6)\end{array}$ & $\begin{array}{c}\text { LOD }^{*} \\
\mathrm{ng} \mathrm{m}^{-3}\end{array}$ & $\begin{array}{r}\text { Reproducibility } \\
\% \\
(n=5)\end{array}$ & $\begin{array}{r}\text { Recovery } \\
\% \\
(n=3)\end{array}$ & $\begin{array}{r}\mathrm{LOD}(\mathrm{ng}), \\
\text { injection volume } \\
25 \mu \mathrm{L}(n=6)\end{array}$ & $\begin{array}{r}\text { LOD* }^{*} \\
\mathrm{ng} \mathrm{m}^{-3}\end{array}$ \\
\hline MA & 2.6 & $86.4 \pm 2.8$ & 3.8 & 0.04 & 12.2 & $55.1 \pm 8.6$ & 2.1 & 0.9 \\
\hline DMA & 3.6 & $99.1 \pm 4.1$ & 1.8 & 0.02 & 15.7 & $60.2 \pm 9.7$ & 3.8 & 1.6 \\
\hline EA & 2.1 & $96.0 \pm 1.8$ & 2.5 & 0.03 & 4.3 & $88.5 \pm 1.9$ & 2.2 & 0.9 \\
\hline DEA & 1.7 & $98.6 \pm 2.1$ & 3.7 & 0.04 & 4.6 & $95.9 \pm 1.5$ & 4.1 & 1.7 \\
\hline TEA & - & - & - & - & 5.1 & $101.3 \pm 1.6$ & 15.9 & 6.4 \\
\hline $\mathrm{PA}$ & 2.0 & $84.3 \pm 1.7$ & 3.7 & 0.04 & - & - & - & - \\
\hline BA & 6.2 & $93.0 \pm 4.9$ & 3.9 & 0.04 & 2.4 & $103.4 \pm 2.3$ & 3.8 & 1.4 \\
\hline
\end{tabular}

* For analyzing a $30 \mathrm{~cm}^{2}$ punch of filters collected with high-volume samplers (sampling at $1.13 \mathrm{~m}^{3} \mathrm{~min}^{-1}$ for $24 \mathrm{~h}$ on $8^{\prime \prime} \times 10^{\prime \prime}$ filters).

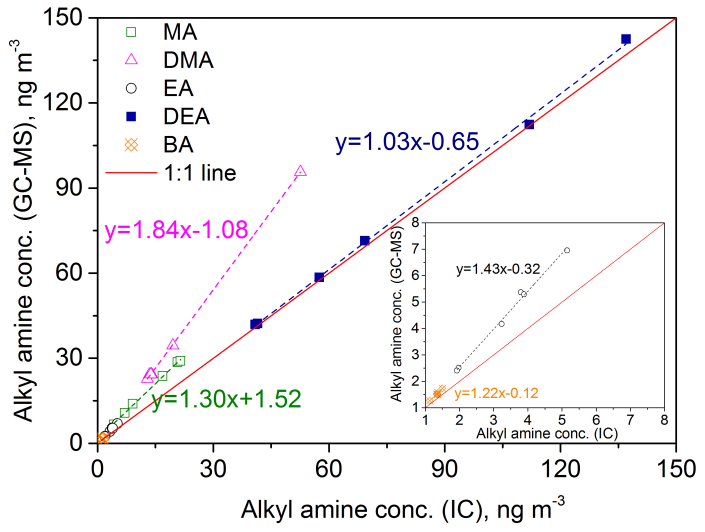

Figure 7. Comparison of GC-MS with IC for the determination of alkylamines in $\mathrm{PM}_{2.5}$. The samples were collected in Tung Chung, Hong Kong.

measured by the IC method (factor between 1.0 and 1.8). This can be attributed to evaporation losses of amines during the sample concentration and SPE separation procedures that are required to minimize interference from other cations for IC quantification of alkylamines. Nevertheless, data from both methods show that DMA and DEA are dominant alkylamines. The seasonal variation of particulate alkylamines measured at this background site in Hong Kong, their sources and atmospheric implications will be published in a separate paper.

\section{Conclusions}

Two analytical approaches, based on GC-MS and IC, for the determination of alkylamines in atmospheric aerosol particles have been evaluated thoroughly in this study. The IC method is subjected to a lower accuracy (55.1-103.4\%) and a higher limit of detection (2.1-15.9 $\mathrm{ng}$, or $0.9-6.4 \mathrm{ng} \mathrm{m}^{-3}$ ) for all alkylamines investigated, due to the lower sensitivity of the conductivity detector and evaporation losses of amines during the sample pretreatment procedure. Compared with the IC method, a significantly higher accuracy (84.3$99.1 \%$ ) and a much lower limit of detection (1.8-3.9 pg, or $0.02-0.04 \mathrm{ng} \mathrm{m}^{-3}$ ) were achieved for the GC-MS method, although the latter is not capable of measuring tertiary amines (an inherent disadvantage of the derivatization GCMS method). The two approaches have been applied to the quantification of low molecular weight alkylamines in the $\mathrm{PM}_{2.5}$ samples collected in Tung Chung, Hong Kong. The application of the GC-MS method revealed slightly higher amine concentrations compared to the IC method. In general, the GC-MS method is superior to the IC method, considering its higher accuracy and lower detection limits, which are crucial for the quantification of alkylamines that are often present at trace levels (from subng $\mathrm{m}^{-3}$ to some hundred $\mathrm{ng} \mathrm{m}^{-3}$ ) in ambient aerosol particles (Ge et al., 2011, and references therein).

Acknowledgements. The research leading to these results has received funding from the European Community's Seventh Framework Programme (FP7/2007-2013) under grant agreement no. 290605 and the National Nature Scientific Foundation of China (21105084). We are grateful to the two anonymous reviewers for their valuable comments and discussion that have greatly improved this paper.

Edited by: P. Herckes

\section{References}

Akyüz, M.: Simultaneous determination of aliphatic and aromatic amines in ambient air and airborne particulate matters by gas chromatography-mass spectrometry, Atmos. Environ., 42, 38093819, 2008.

Angelino, S., Suess, D. T., and Prather, K. A.: Formation of aerosol particles from reactions of secondary and tertiary alkylamines: Characterization by aerosol time-of-flight mass spectrometry, Environ. Sci. Technol., 35, 3130-3138, 2001.

Chan, L. P. and Chan, C. K.: Displacement of ammonium from aerosol particles by uptake of triethylamine, Aerosol. Sci. Tech., 46, 236-247, 2012. 
Erupe, M. E., Liberman-Martin, A., Silva, P. J., Malloy, Q. G. J., Yonis, N., Cocker III, D. R. C., and Purvis-Roberts, K. L.: Determination of methylamines and trimethylamine-N-oxide in particulate matter by non-suppressed ion chromatography, J. Chromatogr. A, 1217, 2070-2073, 2010.

Facchini, M. C., Decesari, S., Rinaldi, M., Carbone, C., Finessi, E., Mircea, M., Fuzzi, S., Moretti, F., Tagliavini, E., Ceburnis, D., and O'Dowd, C. D.: Important Source of Marine Secondary Organic Aerosol from Biogenic Amines, Environ. Sci. Technol., 42, 9116-9121, 2008.

Ge, X. L., Wexler, A. S., and Clegg, S. L.: Atmospheric amines-Part I. A review, Atmos. Environ., 45, 524-546, 2011.

Hallquist, M., Wenger, J. C., Baltensperger, U., Rudich, Y., Simpson, D., Claeys, M., Dommen, J., Donahue, N. M., George, C., Goldstein, A. H., Hamilton, J. F., Herrmann, H., Hoffmann, T., Iinuma, Y., Jang, M., Jenkin, M. E., Jimenez, J. L., Kiendler-Scharr, A., Maenhaut, W., McFiggans, G., Mentel, Th. F., Monod, A., Prévôt, A. S. H., Seinfeld, J. H., Surratt, J. D., Szmigielski, R., and Wildt, J.: The formation, properties and impact of secondary organic aerosol: current and emerging issues, Atmos. Chem. Phys., 9, 5155-5236, doi:10.5194/acp-9-51552009, 2009.

Henning, S., Weingartner, E., Schwikowski, M., Gäggeler, H. W., Gehrig, R., Hinz, K.-P., Trimborn, A., Spengler, B., and Baltensperger, U.: Seasonal variation of water-soluble ions of the aerosol at the high-alpine site Jungfraujoch (3580 m asl), J. Geophys. Res., 108, 4030, doi:10.1029/2002JD002439, 2003.

Hoffmann, T., Huang, R.-J., and Kalberer, M.: Atmospheric analytical chemistry, Anal. Chem., 83, 4649-4664, 2011.

Huang, G., Hou, J., and Zhou, X. L.: A measurement method for atmospheric ammonia and primary amines based on aqueous sampling, OPA derivatization and HPLC analysis, Environ. Sci. Technol., 43, 5851-5856, 2009.

Huang, Y. L., Chen, H., Wang L., Yang, X., and Chen, J. M.: Single particle analysis of amines in ambient aerosol in Shanghai, Environ. Chem., 9, 202-210, 2012.

Junninen, H., Ehn, M., Petäjä, T., Luosujärvi, L., Kotiaho, T., Kostiainen, R., Rohner, U., Gonin, M., Fuhrer, K., Kulmala, M., and Worsnop, D. R.: A high-resolution mass spectrometer to measure atmospheric ion composition, Atmos. Meas. Tech., 3, 10391053, doi:10.5194/amt-3-1039-2010, 2010.

Kameda, T.: Atmospheric chemistry of polycyclic aromatic hydrocarbons and related compounds, J. Health Sci., 57, 504-511, 2011.

Kirkby, J., Curtius, J., Almeida, J., Dunne, E., Duplissy, J., Ehrhart, S., Franchin, A., Gagne, S., Ickes, L., Kuerten, A., Kupc, A., Metzger, A., Riccobono, F., Rondo, L., Schobesberger, S., Tsagkogeorgas, G., Wimmer, D., Amorim, A., Bianchi, F., Breitenlechner, M., David, A., Dommen, J., Downard, A., Ehn, M., Flagan, R. C., Haider, S., Hansel, A., Hauser, D., Jud, W., Junninen, H., Kreissl, F., Kvashin, A., Laaksonen, A., Lehtipalo, K., Lima, J., Lovejoy, E. R., Makhmutov, V., Mathot, S., Mikkila, J., Minginette, P., Mogo, S., Nieminen, T., Onnela, A., Pereira, P., Petaja, T., Schnitzhofer, R., Seinfeld, J. H., Sipila, M., Stozhkov, Y., Stratmann, F., Tome, A., Vanhanen, J., Viisanen, Y., Vrtala, A., Wagner, P. E. Walther, H., Weingartner, E., Wex, H., Winkler, P. M., Carslaw, K. S., Worsnop, D. R., Baltensperger, U., and Kulmala, M.: Role of sulphuric acid, ammonia and galac- tic cosmic rays in atmospheric aerosol nucleation, Nature, 476, 429-433, 2011.

Mäkelä, J. M., Yli-Koivisto, S., Hiltunen, V., Seidl, W., Swietlicki, E., Teinilä, K., Sillanpää, M., Koponen, I. K., Paatero, J., Rosman, K., and Hämeri, K.: Chemical composition of aerosol during particle formation events in boreal forest, Tellus B, 53, 380 393, 2001.

Miyazaki, Y., Kawamura, K., Jung, J., Furutani, H., and Uematsu, M.: Latitudinal distributions of organic nitrogen and organic carbon in marine aerosols over the western North Pacific, Atmos. Chem. Phys., 11, 3037-3049, doi:10.5194/acp-11-3037-2011, 2011.

Müller, C., Iinuma, Y., Karstensen, J., van Pinxteren, D., Lehmann, S., Gnauk, T., and Herrmann, H.: Seasonal variation of aliphatic amines in marine sub-micrometer particles at the Cape Verde islands, Atmos. Chem. Phys., 9, 9587-9597, doi:10.5194/acp-99587-2009, 2009.

Murphy, S. M., Sorooshian, A., Kroll, J. H., Ng, N. L., Chhabra, P., Tong, C., Surratt, J. D., Knipping, E., Flagan, R. C., and Seinfeld, J. H.: Secondary aerosol formation from atmospheric reactions of aliphatic amines, Atmos. Chem. Phys., 7, 2313-2337, doi:10.5194/acp-7-2313-2007, 2007.

Nguyen, T. B., Lee, P. B., Updyke, K. M., Bones, D. L., Laskin, J., Laskin, A., and Nizkorodov, S. A.: Formation of nitrogenand sulfur-containing light-absorbing compounds accelerated by evaporation of water from secondary organic aerosols, J. Geophys. Res., 117, D01207, doi:10.1029/2011JD016944, 2011.

Pan, L., Chong, J. M., and Pawliszyn, J.: Determination of amines in air and water using derivatization combined with solid-phase microextraction, J. Chromatogr. A, 773, 249-260, 1997.

Praplan, A. P., Bianchi, F., Dommen, J., and Baltensperger, U.: Dimethylamine and ammonia measurements with ion chromatography during the CLOUD4 campaign, Atmos. Meas. Tech., 5, 2161-2167, doi:10.5194/amt-5-2161-2012, 2012.

Pratt, K. A., Hatch, L. E., and Prather, K. A.: Seasonal volatility dependence of ambient particle phase amines, Environ. Sci. Technol., 43, 5276-5281, 2009.

Qiu, C. and Zhang, R. Y.: Multiphase chemistry of atmospheric amines, Phys. Chem. Chem. Phys., 15, 5738-5752, 2013.

Ruiz-Jiménez, J., Hautala, S., Parshintsev, J., Laitinen, T., Hartonen, K., Petäjä, T., Kulmala, M., and Riekkola, M.-L.: Aliphatic and aromatic amines in atmospheric aerosol particles: Comparison of three ionization techniques in liquid chromatography-mass spectrometry and method development, Talanta, 97, 55-62, 2012.

Silva, P. J., Erupe, M. E., Price, D., Elias, J., Malloy, Q. G., Li, Q., Warren, B., and Cocker III, D. R.: Trimethylamine as precursor to secondary organic aerosol formation via nitrate radical reaction in the atmosphere, Environ. Sci. Technol., 42, 4689-4696, 2008.

Smith, J. N., Barsanti, K. C., Friedli, H. R., Ehn, M., Kulmala, M., Collins, D. R., Scheckman, J. H., Williams, B. J., and McMurry, P. H.: Observations of aminium salts in atmospheric nanoparticles and possible climatic implications, Proc. Natl. Acad. Sci USA., 107, 6634-6639, 2010.

Sobolevsky, T. G., Revelsky, A. I., Revelsky, I. A., Miller, B., and Oriedo, V.: Simultaneous determination of fatty, dicarboxylic and amino acids based on derivatization with isobutyl chloroformate followed gas chromatography-positive ion chemical ionization mass spectrometry, J. Chromatogr. B, 800, 101-107, 2004. 
Sorooshian, A., Murphy, S. M., Hersey, S., Gates, H., Padro, L. T., Nenes, A., Brechtel, F. J., Jonsson, H., Flagan, R. C., and Seinfeld, J. H.: Comprehensive airborne characterization of aerosol from a major bovine source, Atmos. Chem. Phys., 8, 5489-5520, doi:10.5194/acp-8-5489-2008, 2008.

VandenBoer, T. C., Petroff, A., Markovic, M. Z., and Murphy, J. G.: Size distribution of alkyl amines in continental particulate matter and their online detection in the gas and particle phase, Atmos. Chem. Phys., 11, 4319-4332, doi:10.5194/acp-11-43192011, 2011.
Wang, L., Khalizov, A. F., Zheng, J., Xu, W., Ma, Y., Lal, V., and Zhang, R. Y.: Atmospheric nanoparticles formed from heterogeneous reactions of organics, Nat. Geosci., 3, 238-242, 2010.

Yang, H., Yu, J. Z., Ho, S. S. H., Xu, J. H., Wu, W. S., Wan, C. H., Wang, X. D., Wang, X. R., and Wang, L. S.: The chemical composition of inorganic and carbonaceous materials in $\mathrm{PM}_{2.5}$ in Nanjing, China, Atmos. Environ., 39, 3735-3749, 2005. 